\title{
The Research on the Influencing Factors of
}

\section{Public Service Motivation of Ethnic Minority Civil Servants : Taking the Frontier Area of Yunnan Province, China as a Case}

\author{
Zheng Xiujuan \\ School of Finance and Public Management, \\ Yunnan University of Finance and Economics, Yunnan, P. R. China \\ ynkmcat@126.com
}

\begin{abstract}
The Public Service Motivation(PSM) is essentially an altruistic motive that is universal and non-discriminatory. In the minority areas of Yunnan Province, the proportion of civil servants belonging to minority ethnic groups has been increasing. Their PSM level directly affects social governance, local economic development and cultural development. On the basis of the PSM research scale, this study combined with the PSM preposition factors such as ethnic belonging, ethnic cultural orientation, etc. The study concluded: The sense of belonging and job satisfaction of minority civil servants have a significant negative effect on PSM. Job identification has a significant positive effect on PSM of minority civil servants.
\end{abstract}

\section{Keywords-PSM, Minority, Civil Servant}

\section{INTRODUCTION}

A. Public Service Motivation(PSM) is an important research area for public Management research and practice, which is applied to improve the performance of government services, individual work performance of civil servants and practical innovation.

As a kind of human altruistic motivation, public service motivation is the internal mechanism of individual civil servant, which influences the responsibility, organizational commitment and job satisfaction. There is greater pressure on the implementation of governance changes in minority areas than in developed areas. Civil servants are the bearers of social governance and the acceptors of change. Their internal mechanism influences the efficiency of social governance reform. Current social management relies more on minority civil servants in minority areas of Yunnan Province. By the end of 2016, minority government leaders in Yunnan accounted for 33.68 per cent of the total, an increase of 23 per cent over 2015. 30.24 per cent of the cadres at the county level are from ethnic minorities; 34.74 per cent of the cadres at the section level in villages and towns are from ethnic minorities; 36.50 per cent of civil servants and those involved in public administration at the village and township levels are members of ethnic minorities; 25.95 per cent of the police are ethnic minorities; 28.33 per cent of judges and prosecutors are members of ethnic minorities (Remarkable achievements have been made in training and selecting minority cadres in Yunnan. http://www.sohu.com/a/163821086_543955 2017-08-11). Therefore, the study of public service motivation of minority civil servants is a unique case study of the level of public service motivation of civil servants.

\section{B. Too little research on public service motivation of} ethnic minority public servants

During the period of 1989-2018, there were 39 papers on the study of minority civil servants in China, which mainly focused on the training of the capacity of the minority civil servants, the selection, promotion and the construction of the ranks. However, there is no research on the motivation of public service of ethnic minority civil servants. The core content of this study is to analyze what factors affect the motivation of public servants' service of minority nationality. The purpose of this study is to divide the motivation of public service into three dimensions: emotional motivation, normative motivation and rational motivation. And join the related issues of ethnic identity and national cultural tendency. Through the study of the integration of local social culture and the internal mechanism of individual, it studies its influence on public service motivation, and explores the ways to cultivate and improve the public service quality of civil servants in minority areas.

\section{It is necessary to study public service motivation}

\section{about ethnic minority civil servants}

The reform of social governance is a new challenge for civil servants. The study found that the change of civil servants' job requirements under the background of the deepening of China's reform (restriction / occupation demand), the change of salary and treatment (the decrease or loss of the job consumption / recessive income), which highlighted the important influence of internal motivation on the turnover or retention of civil servants. The motivation of public service has an impact on the subjective and objective satisfaction of civil servants. It is the most important intrinsic motivation in the career development of civil servants.

\section{D.The limited external factors in minority areas make}

the motivation of public service incentive for civil servants more practical.

In the frontier minority areas, many objective conditions have limited the external ways to encourage civil servants. In terms of material incentives, there is a significant gap between wages in the minority areas and those in the 
developed coastal areas. From the survey, we know that most of the salaries of the minority civil servants are 2000 to 3500 . Other welfare benefits are rarely paid. Among them, housing, housing subsidies, Medicaid has also been a problem for civil servants in border areas. To promote the development of civil servants in minority areas, if the external incentives can not be effectively used, it is more realistic to improve the public service motivation of the minority civil servants.

\section{AN OVERVIEW OF EXISTING RESEARCH}

\section{A. The concept of public service motivation (PSM)}

Public service motivation in essence belongs to an altruistic motive. Public service motivation for altruistic object is the social common people, it is a kind of the altruistic motivation of the universality without discrimination. Public service motivation should be the least affected by object factors of an altruistic motive from the ideal conditions. Perry (1996) defines the "public service motivation" as "personal mainly or entirely based on the motivation of public institutions and organizations driven". Rainey and Stein Burry (Rainey \& Stein Burry, 1999) define public service motivation as serving the community, local, national, or human altruism motivation of interest. Mayo's (Someone, 2004) describes the ideal of public service motivation as some concept that close to love. Sense of public service, strong sense of goal and commitment and dedication are included into this ideal model. Van DE ratio (Vandenabeele, 2007) thinks that public service motivation is some kind of belief, values and attitudes beyond the interests of the individuals and departments. It focuses on the interests of a broader political organization, and motivates people at the right time to take the corresponding actions. Perry and Hondeghem, (Perry \& Hondeghem, 2008) argues that the value orientation of public service motivation may be one person.

In the aspect of construct of PSM, Perry \& Wise(1990) viewed that public service motivation stems from three types of motivation, namely, emotional motive, normative motivation and rational motivation. At first, Perry' scale of public service motivation was divided into six dimensions, and was confirmed as four dimensions in the later including attraction to policy making, commitment to the public interest, compassion, Self-sacrifice. So Perry's research made people understand the PSM more clear. After that, Coursey \& Pandy(2007) further reduced the dimensions of PSM into three dimensions including attraction to policy making, commitment to the public interest, compassion.[1] Vandenabeele added the new dimension of democratic governance in his own research and established a scale of five dimensions with 18 items. But the most popular scale of PSM is Perry's scale of four dimensions with 24 item.

\section{B. Research on the dimensions of PSM in China}

Before 2005, 25 papers related to PSM were published. From 2014 to now, there were only 55 articles about the basic concepts of public service motivation. The monograph is "a study of public service motivation - An Empirical Analysis of the motivation of the public service for MPA graduate students in China" (Li Xiaohua, China Social Science Press, 2010). In China, the study of PMS tends to focus on the application of theory in China. As well as the specific description of PSM dimension in Chinese cultural background and the influence of intermediary variables.

A large number of research findings and practical innovations have resulted in the use of PSM theory to improve civil servants' individual work performance and how to manage civil servants. Based on the analysis of the existing theoretical framework and measurement dimensions, a theoretical framework of psychological components of public service motivation is put forward. On this basis, it is found that in Chinese traditional culture, the four dimensions (three components) in the measurement of the motivation of public service in the west, respectively, are sympathized with compassion (emotional motivation), public responsibility (normative motivation), decision-making participation (rational motivation) and self sacrifice, In the process of using the four dimension scale of PSM in China, it was found that the dimension of "compassion" was not verified in China, and the other three dimensions were verified (Liu Bangcheng, 2008), and the "patriotism" "ethics" was added to the Chinese public officials with the four dimension scale. There is a study that the lack of PSM four dimensional questionnaire in China's sympathy dimension is because the PSM motivation of Chinese civil servants is more from the tool performance, not by personal emotional drive is a self-consciousness of professional role norms (Zhang Tingjun, 2012).

In the study of PSM in 12 provinces and cities of China, Li Xiaohua have usesd self realization and policy making as rational motivation. And he taking the public interest and the benefit of the society as the normative level of PSM, taking sympathy as the emotional level of PSM. The questionnaire designed by $\mathrm{Li}$ Xiaohua is composed of 20 topics. The five factor model contains the content of four factor model of western scholars, and it has local adaptability in combination with Chinese cultural background (Li Xiaohua, 2010).

\section{Research on the application of PSM in China}

At present, the application of PSM in China is mainly in the development of measurement dimension and structure, how to use PSM theory to construct the selection mechanism of public management talents, promote public service performance and PSM training.Li Xiaohua analyzed the effect of organizational factors on PSM. The conclusion is that personality and role perception can explain the variation of PSM $30.8 \%$ together; the organizational factors can explain the $30.5 \%$ variation of PSM alone. The combination of three factors can explain the $43.6 \%$ of PSM, and the motivation of enhancing public service can start from these three levels.

Recent studies have focused on the outcome effects of public service motivation,Exploring how the professional behavior of civil servants is affected by the combination of public service motivation。For example, the impact of public service motivation on civil servants 'performance and job satisfaction。Individuals with high public service motivation have higher job satisfaction with higher productivity and lower separation rates in the case of higher personal and organizational matching (Ge Leilei, 2016). Civil servants with high public service motivation show greater compassion, motivation and quality in their work, as well as a high level of organizational identity (Qiuqian, 2017).

The study found that the public service motivation of public sector workers can be used as a key mediating variable between high-commitment work systems and employee advocacy behaviour, which has a significant positive effect on the public service motivation of public sector workers. That is, the high commitment system has a significant positive effect on public service motivation of public sector employees $(=0$. $378, \mathrm{p}<0.01)$, the public service motivation of public sector employees has a significant positive effect on their voice behavior (Liu Bangcheng 2017). 


\section{DATA SOURCE AND VARIABLE MEASUREMENT IN} THIS STUDY

This study adopts the method of PSM questionnaire. After revising some questions of Perry's questionnaire, we use Cousy and Pandey (Cousy and Pandey, 2007) to combine the public interest commitment and self sacrifice as a dimension, and participate in the attraction and sympathy of the policy formulation as a single dimension. The three-dimensional degree corresponds to the three original motives of PSM, the rational motivation, the normative motivation and the emotional motivation, which have joined the demographic characteristics of the respondents, the sense of national identity, and the cultural background of the ethnic groups. The ethnic identity and the altruism of national culture are analyzed as the predominant factors of PSM.

\section{A. Data sources of this study}

The data used in this paper are from the survey of the Department of Sociology of Yunnan University of Finance and Economics from 2015-3 to 2017-10, The survey site was located in the Honghe Yao Autonomous County of Yunnan Province, the Xiaguan city of the Bai Autonomous Prefecture

of Dali and the Mohan port in the Dai Autonomous Prefecture of Xishuangbanna. The survey adopted random sampling method, conducted data collection by government departments at the survey site, distributed 260 questionnaires to civil servants in local government departments, recovered 256 valid questionnaires, and finally obtained 240 valid questionnaires after eliminating invalid questionnaires.

\section{$B$. The overall characteristics of the subject and the level of PSM}

Demographic characteristics of interviewees::Gender structure: male $55 \%$, female $45 \%$. The sex structure of the sample was balanced. Education level: $11.7 \%$ high school and below, $86.6 \%$ junior college to undergraduate degree, $1.7 \%$ master degree. Working life: about $58.3 \%$ of the respondents were less than 10 years. Position: $35 \%$ of the people who have no administrative position. Age structure: the average age of the respondents was 35.08 years.

TABLE 1 THE DESCRIPTIVE FOR PSM

\begin{tabular}{|c|c|c|c|c|}
\hline & $\begin{array}{l}\text { Minim } \\
\text { um }\end{array}$ & $\begin{array}{l}\text { Maxim } \\
\text { um }\end{array}$ & Mean & $\begin{array}{c}\text { Std. } \\
\text { Deviation }\end{array}$ \\
\hline Public service motivation & 2.69 & 4.85 & 3.8436 & .44494 \\
\hline Self-sacrifice & 1.5 & 5.00 & 3.5750 & .71352 \\
\hline Attraction to policy making & 1.00 & 5.00 & 3.7778 & .74325 \\
\hline $\begin{array}{l}\text { Commitment to the public } \\
\text { interest }\end{array}$ & 1.50 & 5.00 & 3.7333 & .75052 \\
\hline Compassion & 1.50 & 5.00 & 4.0871 & .50902 \\
\hline
\end{tabular}

(From the data of this study)

\section{Variable measurement}

\section{1) Dependent Variable}

The dependent variable of this paper is PSM factor. Using the PSM scale of American scholar Pellis (1996), we designed 13 topics to measure the PSM level of ethnic minority civil servants. The choice is from "1= strongly disagree" to "5= strongly agree", assigning $1-5$ points separately. The maximum variance method is used to carry out factor analysis for 13 questions. (KMO=0.618, Cronbach's Alpha coefficient is 0.797). There are 4 factors, namely compassion, self sacrifice, participation in public policy making and public interest commitment.

\section{3) Control Variable}

Referring to previous studies, this paper introduces social population characteristics such as gender, age, nation, educational level, monthly income and administrative level as

\section{2) Independent Variable}

The independent variables include ethnic belonging, working attitude and work identification. Among them, the sense of belonging is measured by "whether you are willing to let others know your ethnic group"; Job satisfaction is a measure of "your satisfaction with your work and income"; Professional identity is measured by "how you feel at work", and the options include three questions: "hard but very successful," "too tired and lacking a sense of achievement" and "very happy". the specific assignment is shown in Table 1.

control variables, and the specific assignment is shown in Table 1. 
TABLE 2 CORRELATION VARIABLE ASSIGNMENT

\begin{tabular}{|c|c|c|c|c|}
\hline & ariable Name & $\begin{array}{l}\text { mean } \\
\text { value }\end{array}$ & $\begin{array}{l}\text { Standard } \\
\text { Deviation }\end{array}$ & Variable connotation \\
\hline $\begin{array}{l}\text { Dep } \\
\text { endent } \\
\text { Variable }\end{array}$ & PSM & 3.844 & 0.445 & $\begin{array}{l}1=\text { A strong disapproval, } 2=\text { Disapproval, } 3= \\
\text { Uncertain, } 4=\text { Endorsed, 5=Strongly Agree }\end{array}$ \\
\hline \multirow{3}{*}{$\begin{array}{l}\quad \text { Ind } \\
\text { ependent } \\
\text { Variable }\end{array}$} & $\begin{array}{l}\text { Ethnic sense } \\
\text { of belonging }\end{array}$ & 1.308 & 0.262 & \multirow{3}{*}{$\begin{array}{l}1=\mathrm{Y}, 0=\mathrm{N} \\
1=\text { Not much care, } 2=\text { Dissatisfied, } 3=\text { More } \\
\text { satisfactory, } 4=\text { Very satisfied } \\
1=\text { Work hard but have a sense of achievement, } \\
\text { 2=Too tired and lacking a sense of achievement, } 3=\text { Very } \\
\text { happy }\end{array}$} \\
\hline & $\begin{array}{c}\text { Job } \\
\text { satisfaction }\end{array}$ & 2.675 & 1.346 & \\
\hline & $\begin{array}{l}\text { Professional } \\
\text { identity }\end{array}$ & 1.733 & 0.508 & \\
\hline & Gender & 1.45 & 0.502 & \multirow{6}{*}{$\begin{array}{l}1=\text { Male, } 0=\text { Female sex } \\
18-90 \text { years old } \\
\text { 1=Ethnic minority, } 0=\text { Han } \\
\text { 1=High school and below, 2= Junior College, } 3= \\
\text { Undergraduate, } 4=\text { Master and above } \\
\text { 1=2000 yuan and below, } 2=2000-3500,3=3500-4000 \text {, } \\
\text { 4=More than } 4000 \text { yuan } \\
\text { 1= Other (no administrative level), } 2=\text { Junior staff, } \\
\text { 3=Intermediate managerial positions, } 4=\text { Senior position, } \\
\text { 5= Departmental level positions }\end{array}$} \\
\hline & Age factor & 35.08 & 8.903 & \\
\hline & Nation, & 3.867 & 2.507 & \\
\hline & $\begin{array}{l}\text { Educational } \\
\text { background }\end{array}$ & 2.40 & 0.718 & \\
\hline & $\begin{array}{l}\text { Monthly } \\
\text { Income }\end{array}$ & 2.150 & 0.659 & \\
\hline & $\begin{array}{l}\text { Administrati } \\
\text { ve Level }\end{array}$ & 3.90 & 0.951 & \\
\hline
\end{tabular}

(From the data of this study)

TABLE 3 THE INFLUENCE MODEL OF PSM ( $\mathrm{N}=60)$

\begin{tabular}{|c|c|c|c|c|}
\hline & Model 1 & Model 2 & Model 3 & Model 4 \\
\hline Gender & $\begin{array}{l}-0.020 \\
(0.126)\end{array}$ & $\begin{array}{c}-0.052 \\
(0.119)\end{array}$ & $\begin{array}{c}0.002 \\
(0.124)\end{array}$ & $\begin{array}{l}-0.002 \\
(0.122)\end{array}$ \\
\hline Age factor & $\begin{array}{c}0.002 \\
(0.009)\end{array}$ & $\begin{array}{c}0.001 \\
(0.009)\end{array}$ & $\begin{array}{l}-0.001 \\
(0.009)\end{array}$ & $\begin{array}{c}0.006 \\
(0.009)\end{array}$ \\
\hline Nation, & $\begin{array}{l}-0.013 \\
(0.026)\end{array}$ & $\begin{array}{l}-0.002 \\
(0.025)\end{array}$ & $\begin{array}{l}-0.012 \\
(0.026)\end{array}$ & $\begin{array}{l}-0.012 \\
(0.026)\end{array}$ \\
\hline Educational background & $\begin{array}{c}0.092 \\
(0.103)\end{array}$ & $\begin{array}{l}0.125 \\
(0.098)\end{array}$ & $\begin{array}{c}0.062 \\
(0.102)\end{array}$ & $\begin{array}{l}0.115 \\
(0.101)\end{array}$ \\
\hline Monthly Income & $\begin{array}{l}0.020^{*} \\
(0.124)\end{array}$ & $\begin{array}{l}-0.001 \\
(0.117)\end{array}$ & $\begin{array}{c}0.023 \\
(0.122)\end{array}$ & $\begin{array}{l}-0.020 \\
(0.122)\end{array}$ \\
\hline Administrative Level & $\begin{array}{l}-0.009 \\
(0.077)\end{array}$ & & $\begin{array}{l}-0.009 \\
(0.076)\end{array}$ & $\begin{array}{c}0.009 \\
(0.075)\end{array}$ \\
\hline $\begin{array}{l}\text { The Sense of Ethnic } \\
\text { Belonging } \\
\text { Subjective satisfaction of } \\
\text { work }\end{array}$ & & $\begin{array}{c}-1.255^{*} * \\
(0.453)\end{array}$ & $\begin{array}{l}-0.077 \\
(0.037) \\
*\end{array}$ & \\
\hline Professional self-identity & & & & $\begin{array}{l}0.146 * \\
(0.070)\end{array}$ \\
\hline Constant term & $\begin{array}{l}3.632 * * \\
* \\
(0.679)\end{array}$ & $\begin{array}{c}4.908 * * * \\
(0.788)\end{array}$ & $\begin{array}{l}3.959 * * \\
* \\
(0.689)\end{array}$ & $\begin{array}{c}3.097 * * * \\
(0.708)\end{array}$ \\
\hline $\mathrm{R} 2$ & 0.035 & 0.159 & 0.091 & 0.070 \\
\hline $\mathrm{F}$ & $0.318^{*}$ & $1.404 *$ & $4.392^{*}$ & $4.385 *$ \\
\hline
\end{tabular}

Notes: (1) The values are non-standard regression coefficients and brackets are standard deviations.;

(2) significant level: $* \mathrm{p}<0.05 ; * * \mathrm{p}<0.01 ; * * * \mathrm{p}<0.001$ 


\section{The RESUlTS OF EMPIRICAL ANALYSIS}

A. In this paper, 4 regression models are established. PMS is the dependent variable, and the independent variables include the sense of ethnic group belonging, job satisfaction and professional identity, in order to investigate the influence factors of the public service motivation of the minority civil servants (Presented in Table 2). The results show that the 4 regression models are all significant at 0.05 level, and have explanatory power for PSM.

B. Model 1 shows that in all control variables, only monthly income has a significant positive impact on the PSM of ethnic minority civil servants $(\beta=0.02, P=0.05)$, and other population variables have no significant impact on PSM. Model 2 showed that after increasing the sense of belonging, the explanatory power increased from $3.5 \%$ to $15.9 \%$, indicating that ethnic affiliation variables help explain PSM better. The results show that the sense of

\section{V . THE CONCLUSION OF DATA ANALYSIS IN THIS STUDY}

A. Demographic characteristics have no significant influence on the PSM level of ethnic minority civil servants. Therefore, there is no specific analysis of demographic characteristics.

B. Ethnic belonging has a significant negative impact on PSM of ethnic minority civil servants. $75 \%$ of respondents said they felt more friendly when they served with their ethnic group. The stronger national identity may lead to the minority civil servants in the work, the professional role consciousness is replaced by the national mutual help consciousness, and then produces the low public service motivation.

C. Job satisfaction includes subjective satisfaction (leadership, colleague relationship, job nature, communication environment) and objective satisfaction (salary, promotion, welfare, and workflow). The objective satisfaction of the minority civil servants has a significant negative impact on the level of PSM. The PSM level of ethnic minority civil servants is lower if they are satisfied with their objective satisfaction. In the narrow employment channels of minority areas, civil servants have become the best choice, and the stability of the civil service profession has become a motive for many people; secondly, the civil servants in minority areas lack opportunities for development, such as the opportunities for learning and career development, so some civil servants work in a negative attitude. The payment of income and working hours has become a sensitive part of minority civil servants in this occupation. According to the survey data, $61.7 \%$ of the respondents chose civil servants' occupation because of the high security of the occupation. $25 \%$ of respondents thought they had no other choice. Therefore, simply increasing the income of civil servants can not improve the PSM level of civil servants in ethnic minority areas.

D. Professional identity has a significant positive impact on PSM of ethnic minority civil servants. PSM is a belief, value and attitude that goes beyond the interests of individuals and departments. It focuses on the interests of more extensive political organizations, and the correct professional beliefs let individuals abandon narrow career ideas. They do not regard ethnic belonging has a significant negative impact on the PSM of ethnic minority civil servants $(\beta=-0.1255, \mathrm{P}=0.01)$, that is, the higher the sense of belonging of the ethnic group, the lower the level of the PSM.

C. After adding job satisfaction variables, the explanatory power of model 3 reached $9.1 \%$, indicating that job satisfaction is an important predictor of PSM for minority civil servants. The results show that the job satisfaction of minority civil servants has a significant negative impact on their PSM level $(\beta=-0.077, \mathrm{p} 0.05)$, The conclusion is that, when minority civil servants are more satisfied with working time and income, the PSM level decreases, which is a question worth further exploring. Model 4 shows that Professional self-identity has a significant positive impact on the PSM level of ethnic minority civil servants (beta $=0.146, \mathrm{P}=0.05$ ), that is, the stronger the Professional self-identity of ethnic minorities, the stronger the level of PSM.

careers as mere means of livelihood. Higher PSM level has a sense of professional responsibility and is less affected by external factors. In ethnic minority areas, individuals with high professional identity have higher public service motivation.

\section{COUNTERMEASURES AND SUGGESTIONS}

\section{A. Improve the organizational factors. Building a}

\section{high commitment work environment}

The high commitment working environment is a working environment with the following characteristics: recruitment selection procedure, business training mechanism, educational education system, future skill development performance assessment system, and smooth information communication in the management system. Studies have found that "responsibility is clear" "to be able to delegate power to the lower level " and "a good trust relationship with the superior", which can significantly improve the PSM level of the civil service.

\section{B. We should change the way of hiring through single}

test, increase the evaluation of personality factors through

\section{the selection process}

There are limited sources of recruitment of civil servants in ethnic minority areas. In the process of selection, the inclination of policy may increase the opportune nature of personal employment. A large number of employment speculation may affect the overall quality of the civil service. Therefore, in recruiting process, we can select more suitable people to enter the civil service through interview and PSM level evaluation.

\section{To promote the cognition of ethnic minority civil}

servants to their professional roles and career planning

\section{guidance for their individuals}

The personal development of civil servants in minority areas is neglected in the current working environment. For example, there are few opportunities for promotion and less 
learning opportunities. Personal development is an important external incentive for civil servants. Clear career planning and strong support for ethnic minority civil servants continue to learn, change the current high-level talent appointment mode. It helps to improve the sense of professional identity of ethnic minority civil servants. High professional identity can improve the PSM level of civil servants.

\section{We need to link job assessment, responsibility}

\section{indicators with pay, and they have been refined}

The compensation system is unreasonable, such as over average, and salary is not subdivided according to job responsibilities. Due to lack of assessment criteria or too general examination, civil servants lack restraint in their work. Such a working environment is favorable for low PSM civil servants, but it inhibits the development desire of high PSM civil servants. Therefore, according to the local working environment to formulate feasible assessment standards, including the refinement and quantification of post requirements, the compensation and post requirements related to the way to achieve the difference in the salary level, play the role of remuneration in the regulation of the efficiency of public service.

\section{E. We need to increase the awareness of PSM in}

\section{minority nationality civil servants}

We should combine the local social development, through the training of the civil service theory, improve the public servants' cognition of the theory of new social governance, establish a new social service pattern, and break away from the narrow sense of mutual benefit. At the same time, we must form a channel for information communication between upper and lower levels. By improving the matching degree between organizational commitment and personal motivation, we can improve the PSM level of minority civil servants.

\section{ACKNOWLEDGEMENT}

This study is grateful to the government of the survey area for its strong support to help us complete the data collection. Thank the research team for working together to complete data analysis and literature collection. This paper is one of the project achievements of the scientific research fund of the Yunnan Provincial Education Department, "Research on the public service motivation of ethnic minority public servants" (project number: 2014Y311).

\section{REFERENCES}

[1] Ge Leilei. The influence of public service motivation on performance of civil servants -- the moderating role of personal organization matching in Shandong Social Sciences 2016, 06 (in Chinese)

[2] Jin Fangfang. On the improvement of incentive mechanism for township officials in western minority areas, Journal of China market 2016, 08 (in Chinese)

[3] Li Xiaohua, PSM research -- An Empirical Analysis of the motivation of MPA graduate student's public service in China, China Social Science Press, 2010:119 (in Chinese)

[4] Liming A cross-cultural study of public service motivation and its Chinese culture based connotation, Psychological Research 2014,7(3): 14-21 (in Chinese)

[5] Li Feng,,etc. Structure and antecedents of public service motivation of grass roots civil servants,Journal of Huazhong Normal University (HUMANITIES AND SOCIAL SCIENCES EDITION) 2016, 01:36 (in Chinese)

[6] Liu Bangcheng, etc. Research on the relationship between high commitment working environment and employee's voice behavior in public sector based on PMS Theory, Journal of management review,2017,01:P62-67 (in Chinese)

[7] Ma Huilan, Chen Maorong. On the path selection of integration of national identity and national identity,Journal of South Central Ethnic Studies (HUMANITIES AND SOCIAL SCIENCES EDITION),2011,7:8 (in Chinese)

[8] Mao Wanlei, etc. The influence mechanism of PSM on job satisfaction of grass-roots civil servants -- Based on the empirical analysis of Shandong, Journal of the Shandong Institute of administration 2017, 07:19 (in Chinese)

[9] Remarkable achievements have been made in training and selecting minority cadres in Yunnan.

http://www.sohu.com/a/163821086_543955 2017-08-11 15:05（in Chinese)

[10] Tan Xinyu, etc. The influence of psychological contract difference on turnover intention of civil servants -- a comprehensive analysis based on public service motivation and change attitude, Journal of Public Administration,2017,10 (in Chinese)

[11] Ye Xianbao \& Lai Guime. Public Service Motivation: Measurement, Compassion and Influence_-Based on the Analysis of the Questionnaire Survey on Samples from Fujian Province. Chinese Public Administration, 2011(8). (in Chinese)

[12] Yang Jingyun, etc.. PSM performance promotion theory and model construction. Social vertical and horizontal 2012,1 (in Chinese 